\title{
Slash 21: A New School and a New Way of Learning
}

\author{
Henk van Dieten \\ Marianum School, Stichting Carmelcollege, Drienerparkweg 16, Hengelo, Netherlands, \\ hdieten@marianum.nl
}

\section{A NEW SCHOOL AND A NEW WAY OF LEARNING}

Slash 21 or $/ 21$ is the name for a whole new kind of school in the Netherlands, a school as a quest for knowledge, where students learn how to study individually as well as together with age peers. That means problem solving, finding solutions quickly and seeing connections between subjects from different disciplines, hence being able to work more easily and more effectively.

To realise this goal, $/ 21$ sees the computer as fundamental in the learning process. Through the creation of an electronic learning environment, using the internet and e-mail, the student has the opportunity to work individually while tuition is still available when necessary.

\section{THE NEW WAY OF LEARNING}

Effective learning depends on the ability to see connections; to combine subjects from different disciplines and thereby create insight into the bigger picture.

The conventional curriculum is converted into two streams: Science and Humanities. The students learn to comprehend the key concepts.

For example, energy is such a key concept. To understand it in all its aspects it is important to use insights from science, chemistry, physics and biology.

$/ 21$ presents those insights in an overall setting and not separated into different subjects. This prevents fragmenting of knowledge.

The original version of this chapter was revised: The copyright line was incorrect. This has been corrected. The Erratum to this chapter is available at DOI: 10.1007/978-0-387-35701-0_35 
That is what is necessary. Our thinking is not bound to the barriers of school subjects. Our community, further education and the labour market require adaptable people. What is required are people trained to be able to find effective solutions in a quick and creative way; people who can combine and are able to see connections.

\section{NEW LANGUAGE TEACHING}

$/ 21$ follows the principles of intensive language teaching. In a twelveweek period, the students will work intensively in four three-hour periods a week on one modern language. From day one they are motivated to speak in a foreign language, encouraged by an English, French or German native speaker who stimulates, interests and corrects whenever necessary.

Again, the initiative of the student is important. By working on educational projects such as reading, observation and listening projects, the student learns to apply the language effectively. The Internet is useful as an exercise technique when e-mail or chat boxes bring students in contact with students in other countries.

\section{THE NEW TEACHER}

New education requires new teachers. The new teacher is called a tutor, a new name for a new function; a tutor that from the first moment on will be in a position to assist and stimulate if and when necessary, and has the time to do so, since the teaching system is flexible and tutors are complementary to one another.

The tutor will have the opportunity to completely focus on his or her key roles as coach, guide, companion and supporter. The tutor observes the progress and results, intercepts and inspires as necessary and helps the student to achieve his or her full potential.

Teaching assistants take certain tasks and responsibilities from the tutor. This, in addition to the use of an electronic learning environment, provides the tutor with the freedom to fulfill his new role.

Together tutors and teaching assistants form a team guided by a team leader. They are responsible for the education of a group of students for three years, thereby encouraging a close bond between students and staff. 


\section{THE NEW GROUP}

Today's youth form groups. Within these groups they gather a wealth of information from one another, they feel free to expose their opinions and emotions. In this situation they support and understand each other by drawing from a huge source of insights and recognition of all aspects of life.

It is the aim of $/ 21$ to work the same way. The majority of the time students will work in smaller or larger groups to fulfill specific tasks. In this natural environment they learn quickly and easily. The result of this system of working together is an improved understanding and a more lasting knowledge due to better and more communication, not to mention the 'feel good' factor.

There are no classes in $/ 21$, just 'home groups' of about 50 students. Three 'home groups' of three subsequent course years are combined into one 'learning community' under the supervision of a staff team.

The members of the 'home group' will quickly know one another, therefore it is easy to split them into small changing groups to carry out work projects. In order to give course-like tuition, 'home groups' from several 'learning communities' will be joined together from time to time.

\section{A NEW BUILDING}

For this type of education, where the pupils are expected to work in smaller or larger groups, a new type of spacious school building is required.

The home base is the heart of $/ 21$. Students and staff of the same 'home group' meet one another in the 'living room' of the school every day. It is the centre of $/ 21$, where social contacts are made and experiences are shared. Ample room is available for groups of students to work on their projects.

It has a mediatheek (library for all kinds of media) and a discovery room with a laboratory, a technical corner as well as an art corner. Obviously the building is designed for desk-independent computer usage. 
7. IMPORTANCE OF ICT

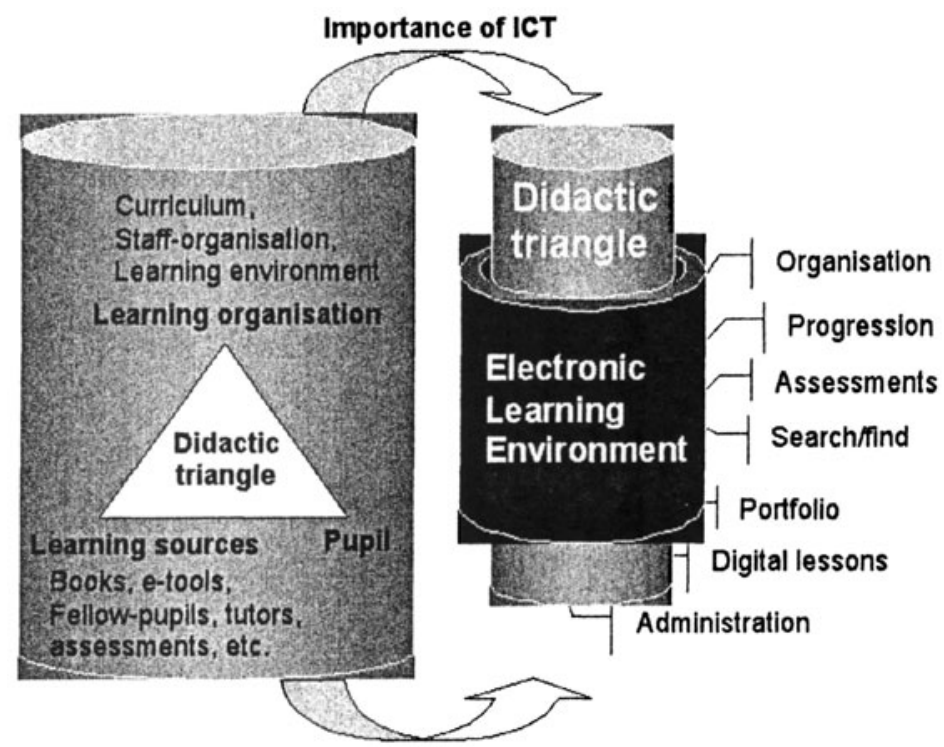

Figure 1. The importance of ICT

All this is possible thanks to the power of ICT as a Learning Management System. It provides sources, brings the real world into school, and helps the monitoring of students, sets tutors free from their task to fill students with knowledge and it is a powerful tool to manage the chaos in this learning space. It is an initiative of the Stichting (Foundation) Carmelcollege and KPC Group.

Slash 21 is an extension of the Marianum School which is a member of the Stichting Carmelcollege.

$/ 21$ is closely related to the Marianum. The Marianum offers a broad scale of education (vmbo, havo and vwo). The Stichting Carmelcollege is one of the largest schoolboards in the Netherlands for secondary education. It is responsible for 35,000 pupils at 20 schools. Our society and labour market have changed drastically in the last decade. The Stichting Carmelcollege is aware of this and takes as its responsibility the provision of appropriate education. $/ 21$ is a logical step for a board that places the pupil in the central role.

The KPC Group is a non profit organization. The KPC groups' major activity is to improve teaching processes. For the government they cooperate in major projects in education innovations. They are also consulted by other schools and school committees to develop ideas in several different areas like school management, personnel and organization. 